17. T. Ohmi, ibid., pp. 251-273.

18. M. Sano, in Proceedings of 10th Workshop on ULSI Ultra Clean Technology, pp. 55-65 May 17, 1991.

19. T. Ohmi, T. Imaoka, I. Sugiyama, and T. Kezuka, This Journal, 139, 3317 (1992).

20. T. Imaoka, T. Kezuka, J. Takano, M. Kogure, T. Isagawa, $\mathrm{H}$. Shimada, and T. Ohmi, in Chemical Proceedings of Semiconductor Pure Water and Chemicals Conference, pp. 162-190, Feb, 1992.
21. T. Shimono and M. Tsuji, Abstract 200, p. 278, The Electrochemical Society Extended Abstracts, Vol. 91-1, Washington, DC, May 5-10, 1991.

22. H. Kikuyama, N. Miki, K. Saka, J. Takano, I. Kawanabe, M. Miyashita, and T. Ohmi, Trans. Semicond. Manuf., SM-3, 99 (1990).

23. H. Kikuyama, N. Miki, K. Saka, J. Takano, I. Kawanabe, M. Miyashita, and T. Ohmi, ibid., SM-4, 26 (1991).

\title{
Loading Effects on Kinetical and Electrical Aspects of Silane-Reduced Low-Pressure Chemical Vapor Deposited Selective Tungsten
}

\author{
Jisk Holleman and Albert Hasper \\ MESA Institute for Microelectronics, Materials Engineering and Sensors and Actuators, \\ University of Twente, 7500 AE Enschede, The Netherlands
}

Chris R. Kleijn

Delft University of Technology, Kramers laboratorium voor Fysische Technologie, 2628 BW Delft, The Netherlands

\section{ABSTRACT}

The growth rate of selective tungsten using tungsten hexafluoride $\left(\mathrm{WF}_{6}\right)$ and silane $\left(\mathrm{SiH}_{4}\right)$ was measured in situ by measuring the time-reflectance curve during selective deposition on a grating or contact window pattern etched in oxide on a silicon substrate. $E x$ situ measurements were performed by step-height and weight-increase measurement. The growth rate and electrical resistivity depend on the loading, i.e., the density of the growing area in a selective deposition. The difference in growth rate between extreme cases, i.e., $100 \%$ vs. $0.04 \%$ growing surface of a 3 -inch wafer for identical flow and pressure conditions can be as high as a factor of 20 . The true surface kinetics were independent of the loading and can be determined quantitatively by calculating the surface partial pressures using a mathematical model. At low growing surface densities, the partial pressures at the wafer surface were approximately equal to the input partial pressures. At large loading, significant differences were calculated between surface and input conditions. The apparent order of growth rate in $\mathrm{SiH}_{4}$ was 1 at low $\mathrm{SiH}_{4} / \mathrm{WF}_{6}$ ratios and increased at a critical $\mathrm{SiH}_{4} / \mathrm{WF}_{6}$ ratio. The order of growth rate in WF $\mathrm{Was}$ $-0.2( \pm 0.05)$ at $\mathrm{SiH}_{4} / \mathrm{WF}_{6}$ ratios below 0.5 and became approximately -0.7 at higher ratios. The temperature dependence of the growth rate was small. The growth rate had a maximum at $300^{\circ} \mathrm{C}$

Tungsten can be used for contact hole and via filling in submicron integrated circuit processes and as a temperature and electromigration resistant metal level in, e.g., sensor and actuator applications. It can be deposited selectively on silicon and metals through the reduction of $\mathrm{WF}_{6}$ by e.g., $\mathrm{Si}, \mathrm{H}_{2},{ }^{1} \mathrm{SiH}_{4},{ }^{2,3} \mathrm{SiH}_{2} \mathrm{~F}_{2},{ }^{4}$ or $\mathrm{GeH}_{4} .{ }^{5}$

The $\mathrm{SiH}_{4}$ chemistry has some advantages over the $\mathrm{H}_{2}$ chemistry, some of which are: lower surface roughness, ${ }^{6,7}$ less chemical attack of the silicon, ${ }^{3,8}$ and high growth rates.

Selective deposition has the advantage that no masks are needed. Problems that still have to be overcome are the selectivity loss, adherence to oxide walls in the contact windows, and the loading effect.

In practice the growth rate and electrical resistivity were strongly dependent from one design to another with different exposed areas. ${ }^{9,10}$ This so-called loading effect is studied here using a grating or contact-window pattern as a measuring device for in situ measurement. ${ }^{11}$ Step-height and weight measurements were used for ex situ measurements. The surface chemistry can be studied independently of gas-phase transport phenomena by calculating the surface concentrations from the input concentrations by using a mathematical model. ${ }^{12}$ When the surface kinetics are known the model can be used in the reverse to predict the loading effects. The in situ measuring method has the advantage that small effects such as very low orders in one of the reactants, which normally would be difficult to establish due to limited reproducibility, can be found.

\section{Experimental}

Experiments were carried out in a cold-wall singlewafer reactor, capable of handling 8 -inch wafers. The ex- periments were performed on 3 -inch silicon wafers at 250 300 , and $360^{\circ} \mathrm{C}$ susceptor temperature. The wafers were oxidized to a thickness of $800 \mathrm{~nm}$ of $\mathrm{SiO}_{2}$. Five different types of test samples with different exposed areas expressed as the micro- and macroloading were used, see Table I.

Growth rates were measured in situ by measuring the time-reflectance curve of the grating or contact-window pattern (samples $i i, i i i, i v$ ). Ex situ measurements were performed by either step-height measurements with a profilometer or by weight-increase measurement. Resistivity measurements were performed with a four-point probe on samples $i$ and $i i$ and according to van der Pauw on samples type $v$. Auger measurements, AES, were performed to measure the Si content on samples $i, i i$, and $v$. Auger electron spectroscopic measurements were performed with a PHI 600 SAM. The analyzed area was about $3 \mu \mathrm{m}^{2}$ at a primary beam energy $E_{\mathrm{p}}=5 \mathrm{kV}$, a beam current of $I=0.5 \mu \mathrm{A}$ and a beam diameter of $2 \mu \mathrm{m}$. The resolution was $0.6 \%$ and the detectability limit was 0.05 atomic percent (a/o). Sensitivity factors were taken from Ref. 13 .

A detailed description of the in situ measurement technique has been presented elsewhere. ${ }^{11}$ The reflectance was measured at a wavelength $(\lambda)$ of $400 \mathrm{~nm}$. In principal the wavelength should be chosen as low as possible to obtain the highest possible resolution. Limited transparency of the viewing window, limited intensity of the white-light source at low wavelengths and problems due to surface roughness at low wavelengths ${ }^{11}$ made us choose the $400-\mathrm{nm}$ wavelength.

The $\mathrm{SiH}_{4}$ flow was varied from $7.5-100 \mathrm{sccm}$ and the $\mathrm{WF}_{6}$ flow from $40-120 \mathrm{sccm}$. The argon flow was kept at $1.5 \mathrm{slpm}$ 
Table I. Description of the sample types used in this study.

\begin{tabular}{|c|c|c|c|}
\hline $\begin{array}{l}\text { Sample } \\
\text { type }\end{array}$ & $\begin{array}{l}\text { Macr } \\
\text { expo: } \\
\text { per } \\
\quad\end{array}$ & $\begin{array}{l}\text { roloading } \\
\text { sed area } \\
\text { r wafer } \\
\% \text { \%) }\end{array}$ & $\begin{array}{l}\text { Microloading } \\
\text { exposed area } \\
\text { wafer center } \\
\quad(\%)\end{array}$ \\
\hline$i$. & $\begin{array}{l}\text { Unpatterned and } \\
\text { unoxidized wafers }\end{array}$ & 100 & 100 \\
\hline ii. & $\begin{array}{l}1 \text { grating pattern } \\
\text { in center, area } \\
\text { outside pattern is } \mathrm{Si}\end{array}$ & 99 & 50 \\
\hline$i i i-1$ & $\begin{array}{l}1 \text { grating pattern } \\
\text { in center, area } \\
\text { outside pattern is oxide }\end{array}$ & 1.1 & 50 \\
\hline$i i i-5$ & $\begin{array}{l}5 \text { grating patterns, } \\
\text { rest as iii-1 }\end{array}$ & 5.5 & 50 \\
\hline$i i i-16$ & $\begin{array}{l}16 \text { grating patterns, } \\
\text { rest as } i i i-1\end{array}$ & 17.5 & 50 \\
\hline$i i i-32$ & $\begin{array}{l}32 \text { grating patterns, } \\
\text { rest as iii-1 }\end{array}$ & 35 & 50 \\
\hline$i v$ & $\begin{array}{l}8 \times 8 \mathrm{~mm} \text { pattern of } \\
10 \mu \mathrm{m} \text { contact windows } \\
\text { with } 10 \mu \mathrm{m} \text { pitch }\end{array}$ & 0.7 & 50 \\
\hline$v$ & $\begin{array}{l}20 \times 40 \mu \mathrm{m} \text { contact } \\
\text { windows at } 15 \mathrm{~mm} \\
\text { distance }+300 \times 300 \mu \mathrm{m} \\
\text { window in center }\end{array}$ & $4 \times 10^{-2}$ & - \\
\hline
\end{tabular}

a The grating pattern is $10 \times 10 \mathrm{~mm}$ and consists of $5 \mu \mathrm{m}$ wide lanes at $5 \mu \mathrm{m}$ distance etched in oxide. The pattern is transferred to the wafer by lithography using a step and repeat camera. The total number of projected patterns is either $1,5,16$, or $32 \times$ and always starts at the center.

and the total pressure at 26.6 Pa (0.2 Torr). The deposition always started with a reaction mixture without $\mathrm{SiH}_{4}$ for $1 \mathrm{~min}$ to form a thin silicon-reduced tungsten layer.

\section{Results}

The reflectance of a grating or contact window pattern is given by

$$
R=\left|\Sigma F_{\mathrm{i}} \cdot r_{\mathrm{i}} \cdot \exp \left(j \delta_{\mathrm{i}}\right)\right|^{2}
$$

where $F_{i}, r_{\mathrm{i}}$, and $\delta_{\mathrm{i}}$ are the surface fraction, the Fresnel reflection coefficient, and the thickness of the fraction covered with material $i$, respectively. ${ }^{11}$ With varying thickness $\delta_{w}$ of tungsten during deposition, the reflectance changes. A typical result of the reflectance of a wafer with $800-\mathrm{nm}$ oxide thickness and 1 grating pattern is presented in Fig. 1. The amplitude of the alternating intensity decreases due to

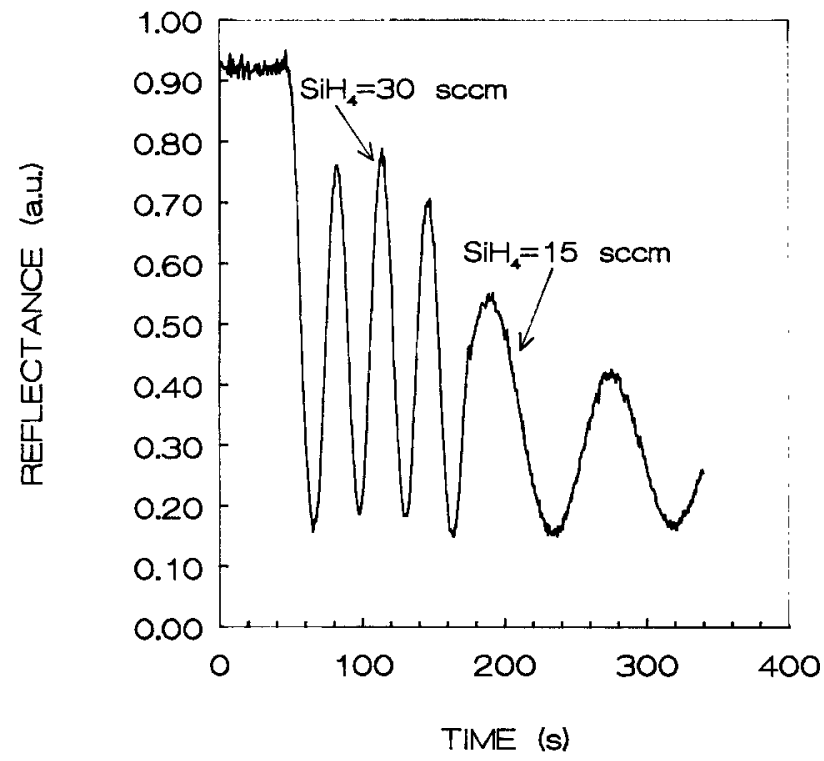

Fig. 1. Reflectance-time curve of a $\mathrm{SiO}_{2}$ covered wafer with one grating pattern (sample type iii-1) eiched in the center. The $\mathrm{SiH}_{4}$ flow rate is changed during selective tungsten deposition. The deposition temperature is $250^{\circ} \mathrm{C}, W F_{6}$ flow $=40 \mathrm{sccm}$, Ar flow $=1500 \mathrm{sccm}$, total pressure is $26.6 \mathrm{~Pa}$ (0.2 Torr).

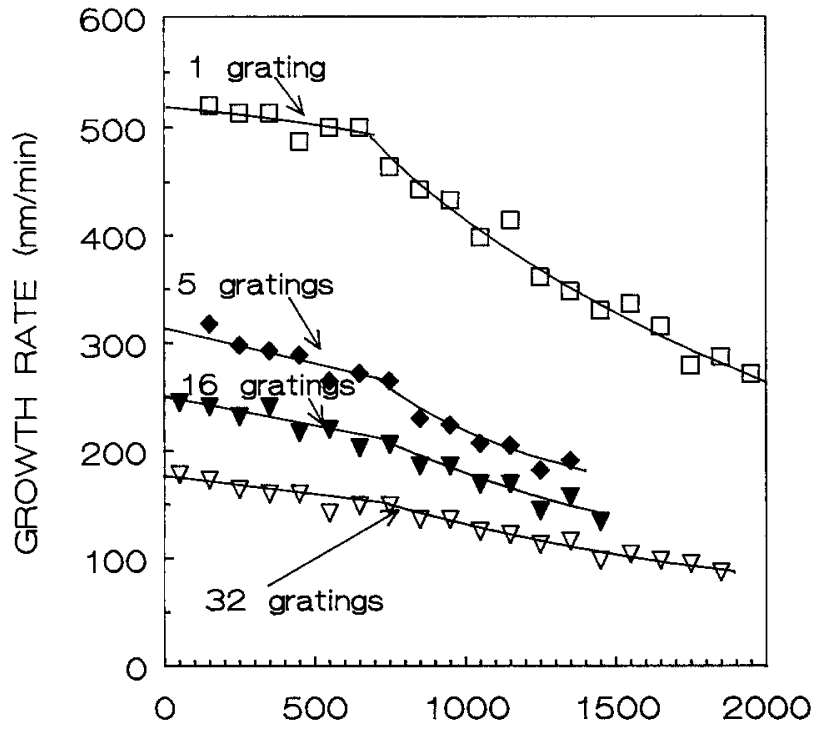

THICKNESS DEPOSITED $(\mathrm{nm})$

Fig. 2. Growth rate vs. deposited thickness on a different number of gratings. Deposition temperature is $300^{\circ} \mathrm{C}, W F_{6}$ flow $=40 \mathrm{sccm}$, $\mathrm{SiH}_{4}$ flow $=30 \mathrm{sccm}, \mathrm{Ar}$ flow $=1500 \mathrm{sccm}$, total pressure $=26.6 \mathrm{~Pa}$ (0.2 Torr).

increasing surface roughness. ${ }^{11}$ The thickness change between two sequential extrema of reflectance corresponds to $\lambda / 4$. This in situ technique is not restricted to a grating but can be applied to irregular contact window patterns as well, provided that the fraction of growing surface is not too small compared to the nongrowing surface.

As shown in Fig. 1, the flow rates can be changed during deposition thus ensuring that all process parameters of both measurements are the same except for the flow rates of $\mathrm{SiH}_{4}$ or $\mathrm{WF}_{6}$. This enables us to establish a low rate order without being disturbed by limited reproducability of independent measurements.

The in situ technique was verified ex situ with a stylus profilometer. There was good agreement between both methods. In growth rates in a contact window we measured only ex situ with a stylus profilometer. No difference in growth rate was measured between the $20 \times 40$ and a $300 \times$ $300 \mu \mathrm{m}$ contact window. Therefore we believe that these growth rates are for the gradientless condition and are determined kinetically. Figure 2 summarizes growth-rate results obtained by reflectometry.

In Fig. 2 the growth rate decreases when the deposited thickness is more than $800 \mathrm{~nm}$. At this thickness the trench formed by the oxide walls is filled and the lateral growth starts. The experiments summarized in Fig. 2 prove that the growth rate depends on the growing surface density on both a macroscale (rate for 1 grating pattern $>32$ grating patterns) and a microscale (rate decreasing with increasing lateral overgrowth). This means that the partial pressure of reactants at the surface decreases during growth due to increasing consuming surface, indicating that transport resistance in the gas phase plays an important role in the growth rate. The small initial slope in Fig. 2 which should be zero can be attributed to a minor early selectivity loss. The initial growth rate, i.e., at zero thickness, determined by extrapolation, has been determined for different $\mathrm{SiH}_{4}$ flow rates, $\mathrm{WF}_{6}$ flow rates, temperatures, and loadings. The initial growth rates are summarized in Fig. 3a and b. Also included in Fig. 3 are the $e x$ situ measurements on sample types $i$ and $v$. An increasing slope can be observed when the growing surface decreases and the $\mathrm{SiH}_{4}$ flow increases.

The resistivity measurements and Auger measurements for $\mathrm{Si}$ content were carried out for the samples deposited at $300^{\circ} \mathrm{C}$ and are presented in Fig. 4.

All results presented in the previous figures were obtained with a fixed flow of $40 \mathrm{sccm} \mathrm{WF}_{6}$. To determine the 


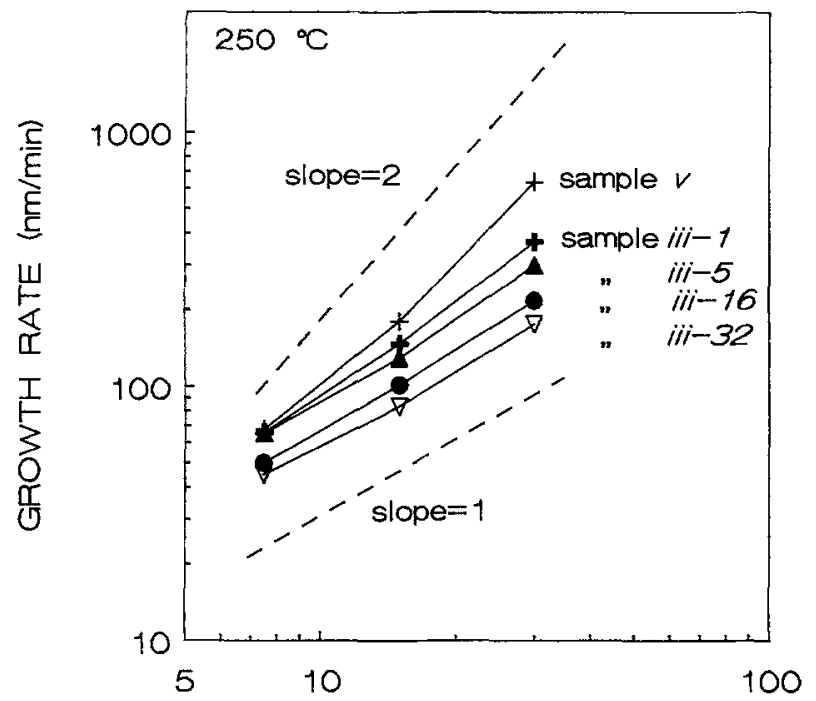

INPUT FLOW OF $\mathrm{SiH} 4$ (sccm)

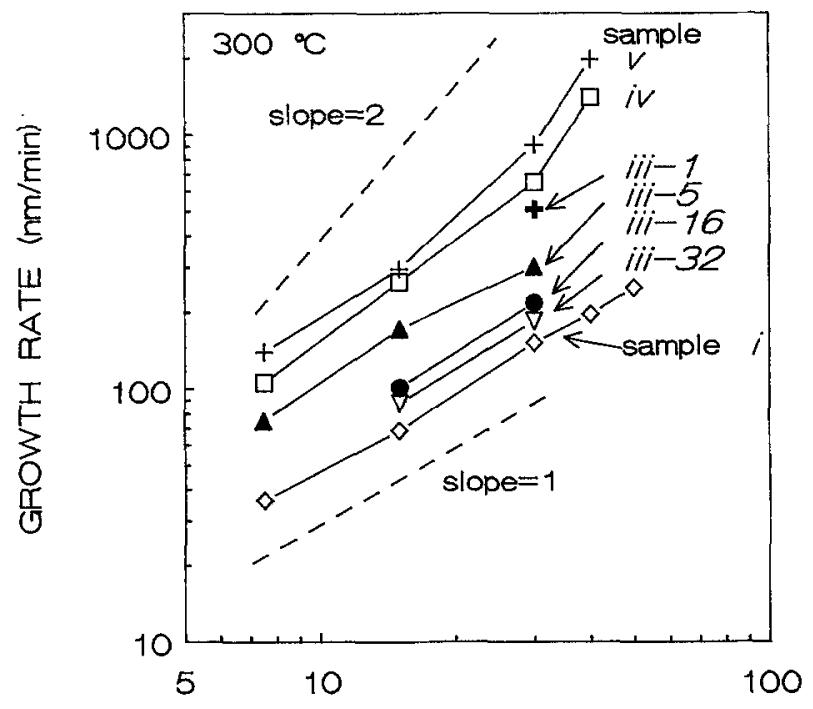

INPUT FLOW OF SiH4 (sccm)

Fig. 3. Initial growth rate for different sample types (Table I) and $\mathrm{SiH}_{4}$ flow rates. WF flow is kept constant at $40 \mathrm{sccm}$, (a, top) $250^{\circ} \mathrm{C}$, (b, bottom) $300^{\circ} \mathrm{C}$.

order of the reaction in $\mathrm{WF}_{6}$ we also performed measurements at various $\mathrm{WF}_{6}$ flows and constant $\mathrm{SiH}_{4}$ flows. These results are presented in Fig. 5. The order of the reaction in $\mathrm{WF}_{6}$ is about -0.2 for $\mathrm{SiH}_{4} / \mathrm{WF}_{6}<0.5$ and becomes more negative for higher ratios.

\section{Growth Kinetics}

Parameter extraction.-For modeling purposes the tungsten growth rate for the $\mathrm{SiH}_{4}$ reduction case can be written as

$$
r=k \cdot\left[p \mathrm{WF}_{6}\right]^{a}\left[p \mathrm{SiH}_{4}\right]^{b} \exp \left(-E_{\mathrm{A}} / R T\right)
$$

where $r$ is the growth rate, $p \mathrm{SiH}_{4}$ and $p \mathrm{WF}_{6}$ are the partial pressures of $\mathrm{SiH}_{4}$ and $\mathrm{WF}_{6}$, respectively, $k$ is a reaction rate constant and $E_{\mathrm{A}}$ is the activation energy. The reaction rate constants $k$ and the exponents $a$ and $b$ are not necessarily constant. This is shown later when equations for growth rate are derived according to a Langmuir-Hinshelwood mechanism. The apparent activation energy $E_{\mathrm{A}}$ has been reported to vary between 0 and $50 \mathrm{~kJ} / \mathrm{mol}^{3,7,8,14-17}$ The rate order in $W_{6}$ has been reported as $-0.6{ }^{17}$ for high $\mathrm{SiH}_{4} / \mathrm{WF}_{6}$

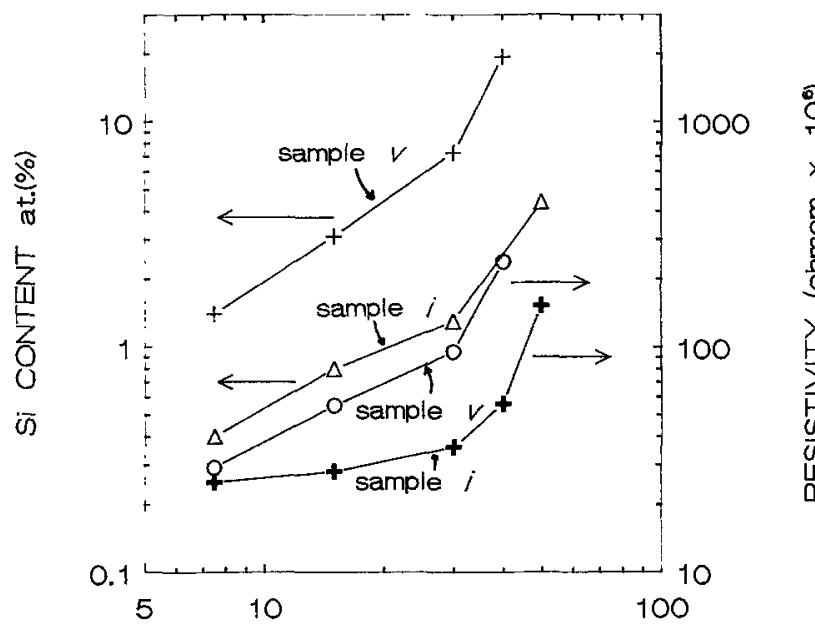

INPUT FLOW OF $\mathrm{SiH} 4$ (sccm)

Fig. 4. Resistivity and Si content for different sample types and $\mathrm{SiH}_{4}$ How rates, $W_{6}$ flow is kept constant at $40 \mathrm{sccm}$.

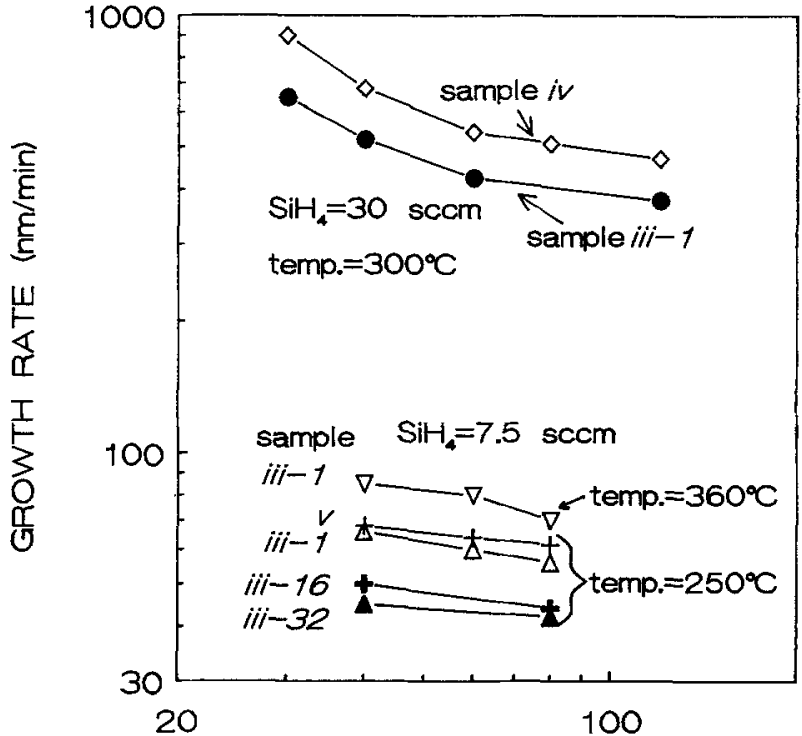

FLOW RATE OF $W_{6}$

Fig. 5. Initial growth rale for different sample types and temperatures vs. WF 6 flow, $\mathrm{SiH}_{4}$ flow rate is kept constant.

ratios and between -0.2 and $0^{7,8,10,14-16}$ for low ratios. For the rate order in $\mathrm{SiH}_{4}$ most authors find a value of 1 for low $\mathrm{SiH}_{4} / \mathrm{WF}_{6}$ ratios, for higher $\mathrm{SiH}_{4} / \mathrm{WF}_{6}$ ratios, values of 1.3 and 2 have been reported. ${ }^{3,7,8,10,15-17}$

To determine the order of the reaction in $\mathrm{SiH}_{4}$ and WF from our results it is not sufficient to plot growth rates against input partial pressures because, as can be concluded from Fig. 2 and 3, the partial pressures at the wafer surface probably vary considerably, depending on the density of exposed area on a wafer.

To analyze the results one needs to know the real partial pressures of $\mathrm{SiH}_{4}, \mathrm{WF}_{6}$, and by-products at the wafer surface. A mathematical simulation model, based on the fundamental transport equations for mass, momentum, heat, and chemical species, and including thermal diffusion (Soret) effects has been used to evaluate the experimental results. The model and its verification by rate measurements and step-coverage predictions in trench-filling with tungsten have been described previously. ${ }^{12,18}$ The experimental growth rates in our study were used as a boundary condition for the species-concentration equations in the mathematical model. To do so one must assume an overall 
Table II. Calculated surface conditions and reactive sticking coefficients.

\begin{tabular}{|c|c|c|c|c|c|c|c|}
\hline \multirow{3}{*}{$\begin{array}{l}\text { Sample } \\
\text { type }\end{array}$} & \multirow{2}{*}{\multicolumn{2}{|c|}{ Input $(\mathrm{sccm})$}} & \multicolumn{2}{|c|}{ Surface conditions } & \multirow[b]{3}{*}{$\mathrm{SiH}_{4} / \mathrm{WF}_{6}$} & \multirow{3}{*}{$\underset{(\mathrm{nm} / \mathrm{min})}{\text { Rate }}$} & \multirow[b]{3}{*}{$\gamma$} \\
\hline & & & \multirow{2}{*}{$\begin{array}{l}\mathrm{SiH}_{4} \\
(\mathrm{~Pa})\end{array}$} & \multirow{2}{*}{$\begin{array}{l}\mathrm{WF}_{6} \\
(\mathrm{~Pa})\end{array}$} & & & \\
\hline & $\mathrm{SiH}_{4}$ & $\mathrm{WF}_{6}$ & & & & & \\
\hline \multicolumn{8}{|c|}{$250^{\circ} \mathrm{C}$} \\
\hline$i i i-1$ & 7.5 & 40 & 0.113 & 0.62 & 0.18 & 66 & 0.059 \\
\hline$v$ & 7.5 & 40 & 0.130 & 0.64 & 0.20 & 68 & 0.053 \\
\hline$i i i-1$ & 7.5 & 60 & 0.113 & 0.93 & 0.12 & 60 & 0.054 \\
\hline$i i i-1$ & 7.5 & 80 & 0.112 & 1.23 & 0.09 & 56 & 0.051 \\
\hline$v$ & 7.5 & 80 & 0.13 & 1.25 & 0.10 & 61.5 & 0.049 \\
\hline$i i i-1$ & 15 & 40 & 0.22 & 0.60 & 0.37 & 147 & 0.068 \\
\hline$v$ & 15 & 40 & 0.26 & 0.63 & 0.41 & 180 & 0.070 \\
\hline$i i i-1$ & 30 & 40 & 0.42 & 0.53 & 0.78 & 371 & 0.091 \\
\hline$v$ & 30 & 40 & 0.51 & 0.63 & 0.82 & 637.5 & 0.13 \\
\hline \multicolumn{8}{|c|}{$300^{\circ} \mathrm{C}$} \\
\hline$i v$ & 7.5 & 40 & 0.12 & 0.61 & 0.20 & 106 & 0.094 \\
\hline$v$ & 7.5 & 40 & 0.13 & 0.62 & 0.21 & 140 & 0.11 \\
\hline$v$ & 15 & 40 & 0.26 & 0.62 & 0.42 & 297 & 0.12 \\
\hline$i i i-1$ & 30 & 30 & 0.36 & 0.31 & 1.16 & 650 & 0.19 \\
\hline$i v$ & 30 & 30 & 0.43 & 0.38 & 1.13 & 900 & 0.22 \\
\hline$i i i_{m} 1$ & 30 & 40 & 0.40 & 0.50 & 0.80 & 480 & 0.15 \\
\hline$i v$ & 30 & 40 & 0.45 & 0.55 & 0.82 & 650 & 0.15 \\
\hline$v$ & 30 & 40 & 0.51 & 0.61 & 0.84 & 847 & 0.17 \\
\hline$i i \bar{i}-1$ & 30 & 60 & 0.40 & 0.80 & 0.50 & 377 & 0.12 \\
\hline iv & 30 & 60 & 0.45 & 0.86 & 0.53 & 550 & 0.13 \\
\hline$i v$ & 30 & 80 & 0.45 & 1.15 & 0.39 & 510 & 0.12 \\
\hline$i i i-1$ & 30 & 120 & 0.40 & 1.67 & 0.24 & 359 & 0.10 \\
\hline$i v$ & 30 & 120 & 0.44 & 1.72 & 0.26 & 470 & 0.11 \\
\hline$i v$ & 40 & 40 & 0.55 & 0.48 & 1.15 & 1400 & 0.27 \\
\hline$v$ & 40 & 40 & 0.68 & 0.61 & 1.11 & 1975 & 0.31 \\
\hline \multicolumn{8}{|c|}{$360^{\circ} \mathrm{C}$} \\
\hline$i i i-1$ & 7.5 & 40 & 0.11 & 0.59 & 0.19 & 88.7 & 0.090 \\
\hline$v$ & 7.5 & 40 & 0.13 & 0.61 & 0.22 & 132 & 0.11 \\
\hline$i i i-1$ & 7.5 & 80 & 0.11 & 1.18 & 0.09 & 68 & 0.068 \\
\hline$i i i-1$ & 15 & 40 & 0.21 & 0.56 & 0.38 & 196 & 0.10 \\
\hline$v$ & 15 & 40 & 0.26 & 0.61 & 0.43 & 290 & 0.12 \\
\hline
\end{tabular}

chemical reaction equation. Kobayashi et $a l .{ }^{19}$ have demonstrated that two reaction paths operate

$$
2 \mathrm{WF}_{6}+3 \mathrm{SiH}_{4} \rightarrow 2 \mathrm{~W}+3 \mathrm{SiF}_{4}+6 \mathrm{H}_{2}
$$

$$
\mathrm{WF}_{6}+2 \mathrm{SiH}_{4} \rightarrow \mathrm{W}+2 \mathrm{SiHF}_{3}+3 \mathrm{H}_{2}
$$

With the second path dominant over the first one.

Reaction path $i i$ was assumed to take place exclusively in our study. The reaction rate was analyzed by rewriting Eq. 2 as

$$
r=1 / 2 \gamma_{\mathrm{s}} \cdot p \mathrm{SiH}_{4} /(2 \pi M R T)^{1 / 2}
$$

with $p \mathrm{SiH}_{4} /(2 \pi M R T)^{1 / 2}$ the surface collision rate of $\mathrm{SiH}_{4}$ and

$$
\gamma_{\mathrm{s}}=2 k \cdot\left[p \mathrm{WF}_{6}\right]^{\mathrm{a}} \cdot\left[p \mathrm{SiH}_{4}\right]^{b-1} \cdot \exp \left(-E_{\mathrm{A}} / \mathrm{RT}\right)
$$

Where $\gamma_{\mathrm{s}}$ is the reactive sticking coefficient of silane, defined as the ratio of the number of silane molecules involved in the reduction reaction of $\mathrm{WF}_{6}$ and the number of silane molecules colliding with the wafer surface, $M$ is the molecular mass of $\mathrm{SiH}_{4}$. Taking the experimental growth rate and the $\mathrm{SiH}_{4}$ surface partial pressures as calculated from the model, $\gamma_{\mathrm{s}}$ was evaluated as

$$
\gamma_{\mathrm{s}}=2 r_{\exp }(2 \pi M R T)^{1 / 2} / p \mathrm{SiH}_{4}
$$

With $r_{\exp }$ the experimentally found growth rate.

The results of the analyses are presented in Table II. The growth rates in Table II are average values.

The experiments with test samples of type $v$ (see Table I) are for the gradientless case, as was pointed out before, and the mathematical model calculates surface concentrations that are equal to the input partial pressures apart from a small difference due to the thermodiffusion effect, which causes the heavy $\mathrm{WF}_{6}$ molecule to be depleted at the surface compared to the input (see Table II). Since the relatively heavy argon gas was used as a carrier gas, the thermodiffusion effect is not pronounced. When $\mathrm{H}_{2}$ is used as a carrier gas, this effect is much more important. ${ }^{12}$ The silane surface partial pressure is almost identical to the inflow conditions for deposition on small reactive areas (sample types $i v, v$, and $i i i-1)$. In these cases, silane depletion is limited, whereas thermodiffusion is almost absent due to the similar molecular masses of $\mathrm{SiH}_{4}$ and $\mathrm{Ar}$. In the case of larger loadings, the silane partial pressure at the surface is significantly lower than the inflow partial pressure, due to silane consumption. Silane depletion is relatively more important than $\mathrm{WF}_{6}$ depletion due to $(i)$ the lower inflow concentrations, and (ii) the stoichiometry of reaction 4 .

In Fig. 6a, b we have plotted the calculated reactive sticking coefficients against the $\mathrm{SiH}_{4} / \mathrm{WF}_{6}$ ratio with constant $\mathrm{WF}_{6}$ partial pressure (Fig. 6a) and constant $\mathrm{SiH}_{4}$ partial pressure (Fig. 6b).

Model predictions of loading effects.-The use of a mathematical simulation model for the fluid flow and transport phenomena in the gas phase, relating the process conditions at the wafer surface to the reactor inlet conditions, allowed us to determine the true surface kinetics as a function of local process conditions, independently of loading effects. We now test the simulation model by evaluating its ability to predict microloading and macroloading effects quantitatively. In these simulations, the deposition rate is calculated from Eq. 5 with the silane partial pressure obtained from the simulation model and $\gamma_{s}$ taken from Fig. 6a. Thus for $\chi=p \mathrm{SiH}_{4} / p \mathrm{WF}_{6} \leq 0.5$ and a fixed $\mathrm{WF}_{6}$ partial pressure of $0.5 \mathrm{~Pa}$, the silane reactive sticking coefficient has a constant value $\gamma_{s}=0.06$ at $250^{\circ} \mathrm{C}$ and $\gamma_{\mathrm{s}}=0.10$ at $300^{\circ} \mathrm{C}$. For $\chi>0.5$, the silane reactive sticking coefficient increases linearly with $\chi$, according to $\gamma_{\mathrm{s}}=0.06+0.14(\chi-0.5)$ at $250^{\circ} \mathrm{C}$ and $\gamma_{\mathrm{s}}=0.10+0.2(\chi-0.5)$ at $300^{\circ} \mathrm{C}$. Assuming these deposition kinetics, growth rates were calculated for varying microloadings. and macroloadings at varying process conditions.

In Fig. $8 \mathrm{a}$ the effect of a varying macroloading at fixed microloading is illustrated. This figure shows model simu- 

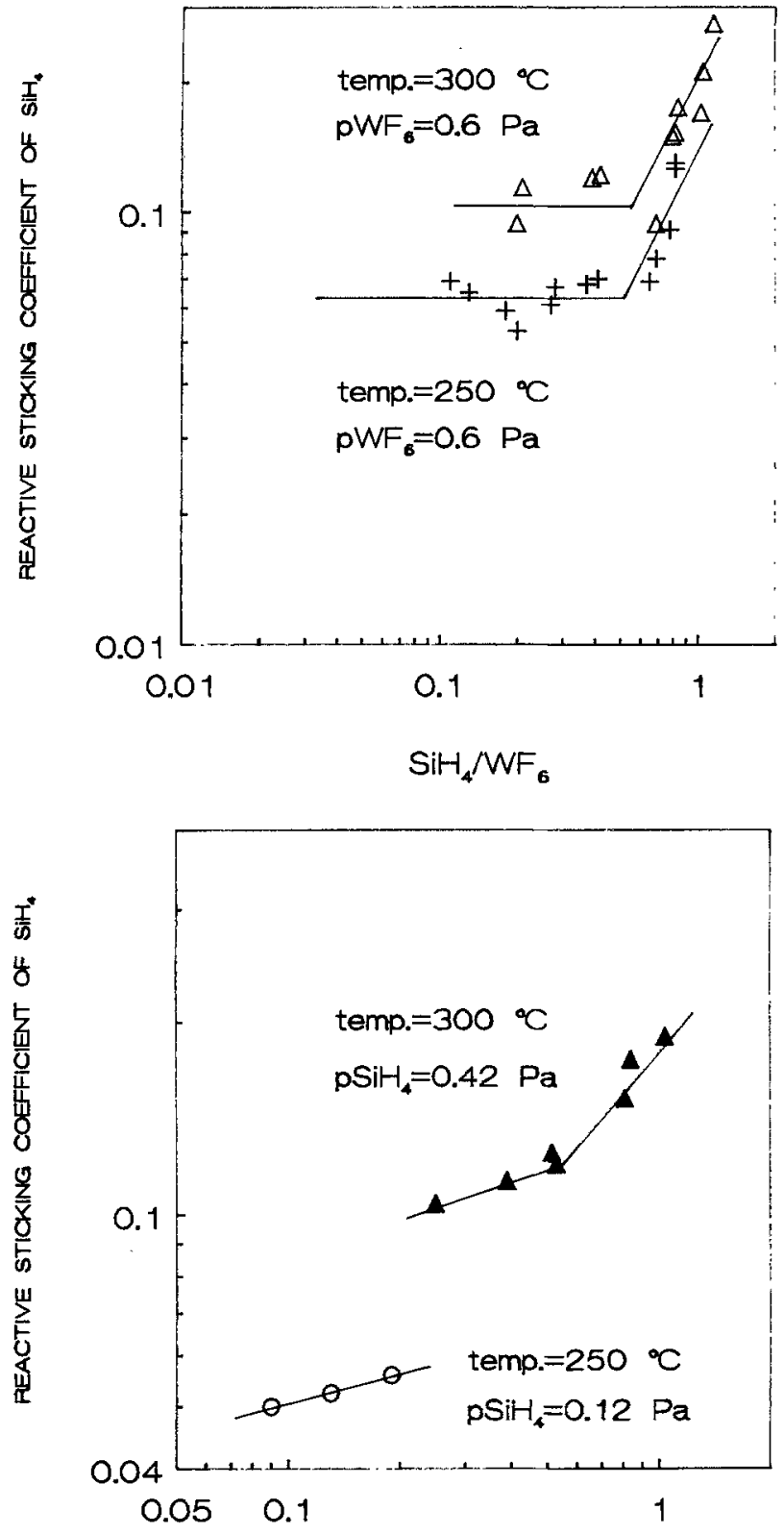

$\mathrm{SiH}_{4} / \mathrm{WF}_{6}$

Fig. 6. Calculated reactive sticking coefficient of $\mathrm{SiH}_{4}, \gamma_{\mathrm{s}}$, vs. calculated $\mathrm{SiH}_{4} / \mathrm{WF}_{6}$ ratio at the surface for: (a, top) $p \mathrm{WF}_{6}=0.6 \mathrm{~Pa}$, and $\mathrm{pSiH}_{4}=$ variable; (b, bottom) $\mathrm{pSiH}_{4}=0.42 \mathrm{~Pa}_{\text {, and }} \mathrm{pSiH}_{4}=0.12 \mathrm{~Pa}$, pWF $=$ variable.

lations and experimental results for the influence of the number of grating patterns on the growth rate, at fixed process conditions. In all cases, the microloading was $50 \%$. The model accurately predicts the decreasing growth rate at increasing macroloading, due to an increased silane depletion. The effect is more pronounced for higher silane flows. This is a result of the second order growth kinetics at high silane partial pressures.

In Fig. $8 \mathrm{~b}$ the effect of a varying microloading at fixed macroloading is illustrated. During deposition, the microloading within a grating pattern, which is initially $50 \%$, increases due to lateral overgrowth (see Results Section) and due to selectivity loss. Outside the grating pattern the initially zero microloading increases during deposition due to loss of selectivity. The lateral overgrowth causes a linear increase of the microloading as function of film thickness, for film thickness exceeding the trench depth. The increase of loading due to selectivity loss is more complex to describe. Following the selectivity loss model by Werner et al., ${ }^{20}$ the fraction $\theta$ of initial oxide surface that is covered with tungsten, as a function of the deposited film thickness $\delta$, is taken as

$$
\theta(\delta)=1-\exp \left(-c \delta^{3}\right)
$$

Here $c=\pi n / 3 r$, with $n$ the nucleation rate and $r$ the deposition rate. The value of $c$ as a function of the location on the surface was deduced from the selectivity loss at the end of the deposition process. Typically, $c$ was of the order of $10^{-11} \mathrm{~nm}^{-3}$, corresponding to nucleation rates of the order of $n=10^{8} \mathrm{~m}^{-2} \mathrm{~s}^{-1}$. For example, in the experiments represented by the upper curve of Fig. 8b, a selectivity loss of 0.3 was observed on the oxide stripes of the grating after the deposition of $2150 \mathrm{~nm}$ tungsten, leading to $c=3.6$ $10^{-11} \mathrm{~nm}^{-3}$. Just outside the grating pattern, the selectivity loss was approximately 0.15 , whereas far away from the grating pattern a selectivity loss of about 0.02 was $\mathrm{ob}-$ served, leading to $c=4.410^{-11} \mathrm{~nm}^{-3}$ and $c=2.010^{-12} \mathrm{~nm}^{-3}$, respectively.

With these assumptions, our simulation model accurately predicts the effect of an increasing microloading on the deposition rate, at fixed macroloading, as can be seen in Fig. 8b. We conclude that our simulation model is capable of quantitatively predicting the effect of both microloading and macroloadings on deposition rates.

Discussion on the reaction mechanism.-The reactive sticking coefficient is more or less constant in Fig. 6a for low $\mathrm{SiH}_{4} / \mathrm{WF}_{6}$ ratios, indicating that the growth rate is indeed first order in silane in a first approximation. However, the apparent order increases beyond a $\mathrm{SiH}_{4} / \mathrm{WF}_{6}$ ratio of about 0.5 . Others $\mathrm{s}^{3,8,21,22}$ found a similar increase and it seems that the $\mathrm{SiH}_{4} / \mathrm{WF}_{6}$ ratio is a more important parameter than the absolute $\mathrm{SiH}_{4}$ partial pressure. Kusumoto et al. ${ }^{3}$ found the increase at $\mathrm{SiH}_{4} / \mathrm{WF}_{6} \sim 1$, Schmitz et al. ${ }^{21}$ at about 1.3. However, these authors use input concentrations and their values were not corrected for thermodiffusion effects or gradients caused by the consuming surface. The second effect is important in Ref. 21 and 22 because these measurements were performed on unpatterned wafers. When we study our results on unpatterned wafers we also find the increase at an input ratio of $\sim 1$. References 3 and 8 used $\mathrm{H}_{2}$ as a carrier gas which causes strong thermodiffusion effects.

From experiments where the $\mathrm{WF}_{6}$ partial pressure was varied during a run we see that $p W_{6}$ has only little influence on the growth rate in the pressure range studied (Fig. 5 and $6 \mathrm{~b}$ ). The order in $\mathrm{WF}_{6}$ was calculated to be about -0.2 for low $\mathrm{SiH}_{4} / \mathrm{WF}_{6}$ ratios and became more negative at a ratio of about 0.5 .

The effect of temperature on growth rate as illustrated in Fig. 7 shows only a little temperature dependence with a maximum at $300^{\circ} \mathrm{C}$ and confirms the results of others. ${ }^{3,16}$

Since the growth rates presented in Fig. 6 and 7 are plotted against the calculated surface concentration, limitation by diffusion can be ruled out and one has to look for mechanisms other than mass transfer to explain the low temperature dependence and the order of the reaction $-\mathrm{in}_{\mathrm{SiH}}$ and $\mathrm{WF}_{6}$. From renucleation experiments using $\mathrm{Si}$ as a layer for renucleation, $\mathrm{SiH}_{4}$ easily reacts to form $\mathrm{Si}$ on $\mathrm{W}$. The reactivity of $\mathrm{Si}$ with $\mathrm{WF}_{6}$ is also very large. ${ }^{1}$ The surface reaction of $\mathrm{WF}_{x}$ compounds with $\mathrm{SiH}_{y}$ compounds is expected to be fast. If one of the compounds is present on the surface in excess it is probably the chemisorption of the minority compound which is the rate-determining step. Because the reactive sticking coefficient of $\mathrm{SiH}_{4}$ is very high and on the order of $10 \%$ of the collision rate we suggest that the chemisorption rate of $\mathrm{SiH}_{4}$ dominates the reaction when $\mathrm{WF}_{6}$ is in excess.

We propose the following set of reactions

$$
\begin{gathered}
\mathrm{WF}_{6}+n^{*} \leftrightarrow \mathrm{WF}_{6}^{*} \\
\mathrm{SiH}_{4}+2^{*} \rightarrow \mathrm{SiH}_{3}^{*}+\mathrm{H}^{*} \\
\mathrm{SiH}_{3}^{*}{ }^{*} \rightarrow \mathrm{SiH}_{2}^{*}+\mathrm{H}^{*} \\
2 \mathrm{SiH}_{2}^{*} \rightarrow 2 \mathrm{SiH}^{*}+\mathrm{H}_{2} \\
2 \mathrm{SiH}^{*} \rightarrow 2 \mathrm{Si}+\mathrm{H}_{2}
\end{gathered}
$$




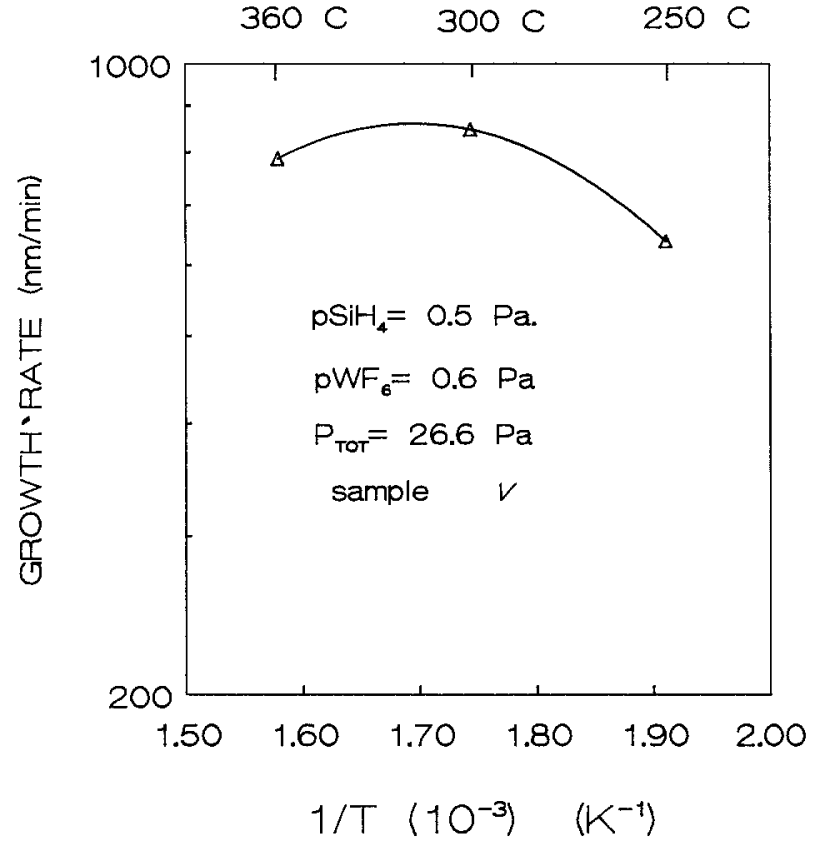

Fig. 7. Arrhenius plots for the growth rate.

$$
\begin{gathered}
\mathrm{WF}_{6}^{*}+\mathrm{SiH}^{*} \rightarrow \mathrm{WF}_{3}^{*}+\mathrm{SiHF}_{3}+* \\
\mathrm{WF}_{3}^{*}+\mathrm{SiH}^{*} \rightarrow \mathrm{W}+\mathrm{SiHF}_{3}+n * \\
2 \mathrm{WF}_{6}^{*}+3 \mathrm{Si} \rightarrow 2 \mathrm{~W}+3 \mathrm{SiF}_{4}
\end{gathered}
$$

* denotes a free surface site, $X^{*}$ denotes an adsorbed molecule or radical.

$\mathrm{WF}_{6}$ and $\mathrm{SiH}_{4}$ when adsorbed to the surface shield more than one site either because their Lennard Jones diameters of 0.572 and $0.408 \mathrm{~nm}$, respectively, are larger than the average $\mathrm{W}-\mathrm{W}$ distance in tungsten of $0.25 \mathrm{~nm}$ or because the chemisorption is dissociative. $\mathrm{WF}_{6}$ is assumed to adsorb reversibly on $n$ sites and $\mathrm{SiH}_{4}$ is supposed to adsorb irreversibly on two sites, an assumption generally adopted for $\mathrm{SiH}_{4}$ chemisorption in Si deposition. ${ }^{23} \mathrm{WF}_{6}$ when adsorbed to the surface probably dissociates as was indicated by the work of Hindman et al. ${ }^{24} \mathrm{WF}_{6}^{*}$ and also $\mathrm{WF}_{3}^{*}$ then may be regarded as $\mathrm{WF}_{x}^{*}$ and $\mathrm{F}^{*}$ on adjacent sites. Such an approach does not change the basic equations for the calculation of surface radicals and reactions. The reaction scheme leads to

$$
\begin{gathered}
\mathrm{WF}_{6}^{*}=k_{1} p \mathrm{WF}_{6}\left({ }^{*}\right)^{n} /\left(k_{-1}+k_{6} \mathrm{SiH}^{*}\right) \\
\mathrm{WF}_{3}^{*}=k_{6} / k_{7} \mathrm{WF}_{6}^{*} \\
\mathrm{SiH}^{*}=k_{2} p \mathrm{SiH}_{4}\left({ }^{*}\right)^{2} / 2 k_{6} \mathrm{WF}_{6}^{*}
\end{gathered}
$$

Assuming that $\mathrm{WF}_{6}^{*}+\mathrm{WF}_{3}^{*} \gg \mathrm{SiH}^{*}$ we obtain

$$
*=1 / 1+\left(1+k_{6} / k_{7}\right) K_{1} p \mathrm{WF}_{6} *(n-1)
$$

with

$$
K_{1}=k_{1} / k_{-1}+k_{6} \mathrm{SiH}^{*}
$$

If we write $\left(1+k_{6} / k_{7}\right) K_{1}$ as $K$ we get

$$
*=1 / 1+K p \mathrm{WF}_{6}^{1 / e}
$$

with $e=n$ for large surface occupancy and $e=1$ for low surface occupancy. The growth rate is then given by

$$
r=k_{2} p \mathrm{SiH}_{4} / 2\left(1+K p \mathrm{WF}_{6}^{1 / /}\right)^{2}
$$

If the flux of $\mathrm{SiH}_{4}$ to the surface is increased the rate of consumption of $\mathrm{WF}_{6}^{*}$ may become so large that in Eq. 12 $k_{6} \mathrm{SiH}^{*} \gg k_{-1}$. This leads to a change in the rate expression. Since $\mathrm{SiH}^{*}$ is proportional to $p \mathrm{SiH}_{4}$ and inversely proportional to $p \mathrm{WF}_{6}$ this leads to an increase in the $\mathrm{SiH}_{4}$ order and a decrease in the $\mathrm{WF}_{6}$ order.

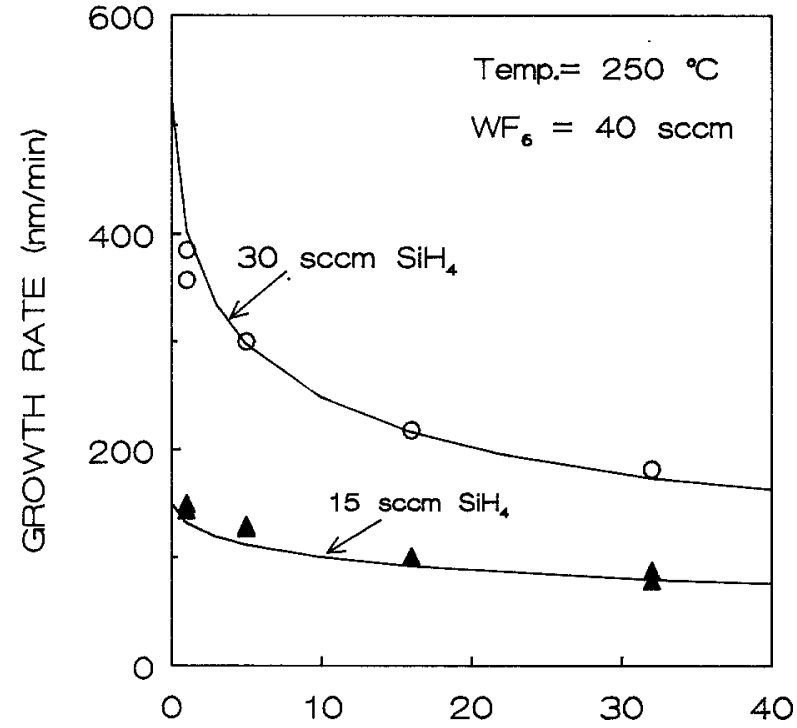

NUMBER OF GRATINGS

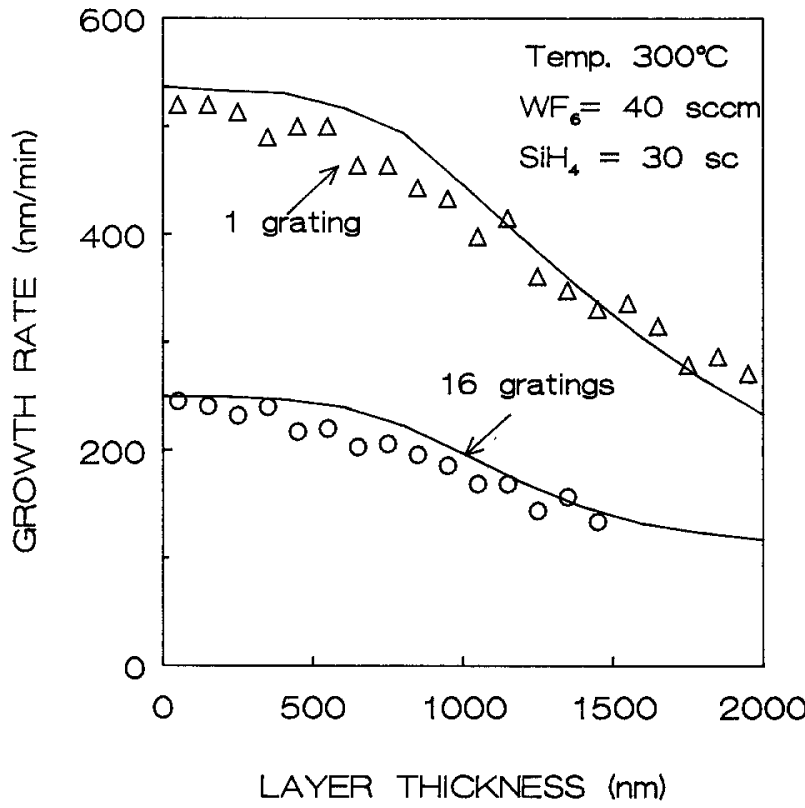

Fig. 8. Model verification for (a, top) variable macroloading; and (b, bottom) variable microloading. Measurements are indicated by markers, solid lines are model calculations.

The observed behavior can be understood, i.e., $(i)$ linear in $p \mathrm{SiH}_{4}$ at low $p \mathrm{SiH}_{4}$, (ii) little thermal activation in agreement with adsorption to be rate-determining; and (iii) order in $\mathrm{WF}_{6}$ is negative.

At low $\mathrm{SiH}_{4} / \mathrm{WF}_{6}$ ratios the negative order is small $(\cong-0.2)$. The apparent order is determined by the free surface and the number of sites involved in $\mathrm{WF}_{6}$ and $\mathrm{SiH}_{4}$ chemisorption (Eq. 13). At higher ratios the order in $\mathrm{SiH}_{4}$ increases and the order in $\mathrm{WF}_{6}$ becomes more negative. The critical ratio at which the growth rate increases is controlled by the relative fluxes of $\mathrm{WF}_{6}$ and $\mathrm{SiH}_{4}$ rather than the absolute values of the pressures as was found by several authors ${ }^{3,8,21,22}$ all working at different pressures.

A further increase of the $\mathrm{SiH}_{4}$ flux produces layers with Si in excess according to R-5 as was found by others ${ }^{21,22}$ and $\mathrm{WF}_{6}$ chemisorption gradually becomes rate-determining.

A second reaction path which should not be ignored is the gas-phase reaction. A radical chain gas-phase reaction with upper and lower pressure limits may explain the anomalous growth rate observed at certain ratios of $\mathrm{SiH}_{4}$ and $\mathrm{WF}_{6}$. There are reasons to assume that in the higher-order regime gas-phase reactions play a role. Facts that sup- 
port the assumption of a gas-phase reaction are: $(i)$ by Fourier-transform infrared spectroscopy Nakamura et al. ${ }^{25}$ observed gas-phase reactions in the range of $\mathrm{SiH}_{4} /$ $\mathrm{WF}_{6}=0.7-1$. The gas-phase reactions were accompanied by luminescence; (ii) at $\mathrm{SiH}_{4} / \mathrm{WF}_{6}$ ratios of $\cong 1$, although measured at a higher total pressure, particle formation was observed in situ with a particle counter ${ }^{26}$; (iii) in the higher order regime blobs are formed in the $\mathrm{W}$ layer ${ }^{3}$; $(i v)$ the onset of higher order regime is also the onset of early selectivity loss and nonselective deposition; $(v) \mathrm{WF}_{6}$ and $\mathrm{SiH}_{4}$ were sometimes found to react already at room temperature in our reactor. At the gas entrance where $\mathrm{WF}_{6}$ and $\mathrm{SiH}_{4}$ meet in the reactor a blackish powder-like deposit could be formed depending on pressure conditions; and (vi) the surface roughness was larger in the higher-order regime.

The limited information that can be obtained from growth rates alone cannot decide the relative importance of the mentioned reaction paths. Analyses of the surface by, for example TPD, as was done for the $\mathrm{H}_{2}$ reduction of $\mathrm{WF}_{6}{ }^{24}$ and analyses of the gas phase by, e.g., mass spectrometry and optical techniques such as LIF or FTIR ${ }^{25,27}$ are necessary to decide about possible gas-phase reaction paths and their relative importance.

We observed that the selectivity loss in the regime of $0.5<$ $\mathrm{SiH}_{4} / \mathrm{WF}_{6}<0.8$ is still initiated by the growing surface, i.e., the selectivity loss occurs first at the edge of the growing surface. The observed gas-phase reactions ${ }^{25,26}$ in the same regime may well have the same source, namely, that gasphase nuclei may grow in an enhanced fashion due to the enhanced reaction on the growing surface of the nucleus.

An apparent order increase also may be attributed to a density change due to void formation or Si incorporation in the layer. Schmitz et al. ${ }^{21}$ and Suzuki et $a l^{22}$ found that for $\mathrm{SiH}_{4} / \mathrm{WF}_{6}>1.0$ large quantities of silicon start to be incorporated in the film. Their ratio of 1.0 may well correspond to our 0.5 . If such a phenomenon does take place, our kinetic discussion may start to fail, because we translate a growth in nanometeres to $\mathrm{W}$ atoms assuming that the layer is pure tungsten with a density of 19.3. To exclude such errors we calculated the density of the layer from weight and thickness measurements on test samples type $i$ and $i i$ along with Si content measurements by Auger (Fig. 4), and found that the density varies between 17.5 and 19.5 for $\mathrm{SiH}_{4} / \mathrm{WF}_{6}$ ratios below 0.8 . However, when the input ratio is around 1.0, we found, in general, similar values but sometimes we also found densities as low as 11.5 with a low degree of reproducibility. In the case of growth in contact windows we could not measure the density but with AES we found Si content as large as $15 \mathrm{a} / \mathrm{o}$ (Fig. 6). The calculated $\mathrm{SiH}_{4} / \mathrm{WF}_{6}$ ratio in that case was 1.11 . Hence the increasing reactive sticking at $\mathrm{SiH}_{4} / \mathrm{WF}_{6}>0.8 \mathrm{can}$ in part be attributed to the increasing Si content.

The reason why the $\mathrm{Si}$ content in the $\mathrm{W}$ in contact windows is larger than on unpatterned Si wafers is explained under the discussion on Electrical Aspects.

\section{Electrical Aspects}

The resistivity of $\mathrm{SiH}_{4}$-reduced selective tungsten increases with increasing Si content in the layer. ${ }^{21,22,28}$ The Si content increases with increasing $\mathrm{SiH}_{4} / \mathrm{WF}_{6}$ ratio as well as with decreasing deposition temperature. At a critical ratio of $\sim 1$ the Si content increases rapidly accompanied by selectivity loss, density change, and morphology change.

By controlling the temperature of the susceptor, the wafer temperature then depends, among ôther things on the effective emission coefficier.t of the front side ${ }^{29}$ which is related to the density of the growing area: Also, the $\mathrm{SiH}_{4} /$ $\mathrm{WF}_{6}$ ratio at the wafer surface depends on the exposed area. The effect of loading as presented in Fig. 4 can be explained as follows: ( $i$ ) in the case of test'samples $i$ and $i i$ the temperature is at its highest because of the low emission coefficient of the tungsten. The $\mathrm{SiH}_{4} / \mathrm{WF}_{6}$ ratio at comparable flows is the lowest because these samples have a large exposed area. Both the higher temperature and the lower $\mathrm{SiH}_{4} / \mathrm{WF}_{6}$ ratios cause these samples to have the lowest silicon content and resistivities; and (ii) in the case of samples $v$ the temperature is the lowest because the energy- emitting surface mainly consists of $0.8-\mu \mathrm{m}$ oxide-covered $\mathrm{Si}$ and the ratio is at its highest due to the low total consumption of reacting agents causing these samples to have their highest Si content and resistivity at comparable flows.

\section{Conclusions}

The loading effects observed on growth rate, Si content, and electrical resistivity in the deposition of tungsten $\mathrm{WF}_{6}$ and $\mathrm{SiH}_{4}$ can be attributed to gradients of $\mathrm{SiH}_{4}$ in the gas phase caused by the reactant-consuming surface. These effects can be predicted quantitatively with a mathematical simulation model.

The density of the growing surface determines not only the true surface concentration but also the wafer temperature. The Si content and the resistivity of the $\mathrm{W}$-layer, which is determined by temperature and $\mathrm{WF}_{6} / \mathrm{SiH}_{4}$ ratio at the surface, becomes loading-dependent.

The order of the reaction in $\mathrm{SiH}_{4}$ is 1 and increases at $\mathrm{SiH}_{4} / \mathrm{WF}_{6}$ ratios $>0.5$.

The apparent order in $\mathrm{WF}_{6}$ is -0.2 at $\mathrm{SiH}_{4} / \mathrm{WF}_{6}$ ratios below 0.5 . At higher ratios the order decreases.

The rate determining step is probably the chemisorption of $\mathrm{SiH}_{4}$, which explains the low activation energy and the small negative order in $\mathrm{WF}_{6}$ at low $\mathrm{SiH}_{4} / \mathrm{WF}_{6}$ ratios.

\section{Acknowledgment}

The authors thank Gerrit ten Bolscher for his assistance in the experiments, Albert van den Berg for performing the AES measurements, and John Baxter for correction of the English. The authors also thank Dr. A. E. T. Kuiper of the Philips Research Laboratories and Ir. J. Ammerlaan of the University of Delft for the valuable discussions on the kinetic aspects and on the loading effects. We greatly appreciate the financial support from the Innovatief Onderzoeks Programma IC technology (Innovative Research Program for IC technology).

Manuscript submitted April 23, 1992; revised manuscript received Nov. 20, 1992.

The University of Twente assisted in meeting the publication costs of this article.

\section{REFERENCES}

1. E. K. Broadbent and C. L. Ramiller, This Journal, 131, 1427 (1984).

2. R. F. Foster, S. Tseng, and L. Lane, in Tungsten and Other Refractory Metals for VLSI Applications III, Wells, Editor, p. 69, Materials Research Society, Pittsburgh (1988).

3. Y. Kusumoto, K. Tawakuwa, H. Hashinokuchi, T. Ikuta, and I. Nakayama, ibid., p. 103.

4. H. Goto, N. Kobayashi, and Y. Homma, in ULSI-VII 1992, V. V. S. Rana, R. V. Joshi, and I. Ohdomari, Editors, p. 135, Materials Research Society, Pittsburgh (1992).

5. G. J. Leusink, C. A. van der Jeugd, T. G. M. Oosterlaken, G. C. A. M. Janssen, and S. Radelaar, ibid., p. 143.

6. J. Holleman, A. Hasper, and J. Middelhoek, in Chemical Vapor Deposition of Refractory Metals and Ceramics, T. M. Besman and B. M. Gallois, Editors, p. 107, MRS Symposium Proceedings, Vol. 168, Materials Research Society, Pittsburgh (1990).

7. A. Hasper, J. Holleman, and J. Middelhoek, in Tungsten and Other Advanced Metals for ULSI Applications VI, G. C. Smith and R. Blumenthal, Editors, p. 317 , Materials Research Society, Pittsburgh (1991).

8. R. S. Rosler, J. Mendoca, and M. J. Rice, J. Vac. Sci. Technol., B6, 1721 (1988).

9. T. Suzuki, N. Misawa, T. Hara, T. Ohba, and Y. Furumura', in Tungsten and Other Advanced Metals for VLSI/ULSI Applications V, S. S. Wong and S. Furukawa, Editors, p. 267, Materials Research Society, Pittsburgh (1991).

10. J. Holleman, A. Hasper, and C. R. Kleijn, in Advanced Metallization for ULSI Apptications, V. V. S. Rana, R. V. Joshi, and I. Ohdomari, Editors, p. 241, Materials Research Society, Pittsburgh (1992).

11. J. Holleman, A. Hasper, and J. Middelhoek, This Jour$n a l, 138,989$ (1991). 
12. C. R. Kleijn, A. Hasper, C. J. Hoogendoorn, J. Holleman, and J. Middelhoek, ibid., 138, 511 (1991).

13. L. E. Davis, N. C. MeDonald, P. W. Palmberg, G. E. Riach, and R. E. Weber, Handbook of Auger Electron Spectroscopy, Physical Electronics Division of Perkin-Elmer Corporation.

14. H. Goche, T. Sahin, and J. T. Sears, in Tungsten and Other Advanced Metals for VLSI/ULSI Applications $V$, S. S. Wong and S. Furukawa, Editors, p. 103, Materials Research Society, Pittsburgh (1990).

15. H. L. Park, S. S. Yoon, C. O. Park, and J. S. Chun, Thin Solid Films, 181, 115 (1989).

16. J. E. J. Schmitz, A. J. M. van Dijk, and M. W. M. Graef, in Proceedings of the 10th International Conference on Chemical Vapor Deposition 1987, G. W. Cullen, Editor, PV 87-8, p. 625, The Electrochemical Society Softbound Proceedings Series, Pennington, NJ (1987).

17. T. Ohba, T. Suzuki, and T. Hara, in Tungsten and Other Refractory Metals for VLSI Applications IV, R. S. Blewer and C. M. McConica, Editors, p. 17, Materials Research Society, Pittsburgh (1989).

18. A. Hasper, J. Holleman, J. Middelhoek, C. R. Kleijn, and C. J. Hoogendoorn, This Journal, 138, 1729 (1991).

19. N. Kobayashi, H. Goto, and M. Suzuki, in Tungsten and Other Advanced Metals for ULSI Applications VI G. C. Smith and R. Blumenthal, Editors, p. 143, Materials Research Society, Pittsburgh (1991).

20. C. Werner, L. I. Ulacia F., C. Hopfmann, and P. Flynn,
This Journal, 139, 566 (1992).

21. J. E. J. Schmitz, M. J. Buiting, and R. C. Elwanger, in Tungsten and Other Refractory Metals for VLSI Applications IV, R. S. Blewer and C. M. McConica, Editors, p. 17, Materials Research Society, Pittsburgh (1989).

22. M. Suzuki, N. Kobayashi, K. Mukai, and S. Kondo, This Journal, 137, 3213 (1990).

23. S. M. Gates, C. M. Greenlief, S. K. Kulkarni, and H. H. Sawin, J. Vac. Sci. Technol. A, 8, 2965 (1990).

24. G. T. Hindman and G. B. Raupp, in Advanced Metallization for ULSI Applications, V. V. S. Rana, R. V. Joshi, and I. Ohdomari, Editors, p. 53, Materials Research Society, Pittsburgh (1992).

25. Y Nakamura, N. Kobayashi, H. Goto, and Y. Homma, in Extended Abstracts of the 1991 International Conference on Solid State Devices and Materials, p. 216.

26. E. J. McInerney, T. W. Mountsier, B. L. Chin, and E. K. Broadbent, in Advanced Metallization for ULSI Applications, V. V. S. Rana, R. V. Joshi, and I. Ohdomari, Editors, p. 69, Materials Research Society, Pittsburgh (1992).

27. H. Goto, N. Kobayashi, and Y. Homma, ibid., p. 135.

28. C. A. Van Der Jeugd, A. H. Verbruggen, G. J. Leusink, G. C. A. M. Janssen, and S. Radelaar, in Tungsten and Other Advanced Metals for VLSI/ULSI Applications $V$, S. S. Wong and S. Furukawa, Editors, p. 267, Materials Research Society, Pittsburgh (1991).

29. A. Hasper, J. E. J. Schmitz, J. Holleman, and J. F. Verweij, J. Vac. Sci. Technol. A, 10, 3193 (1992).

\title{
Effect of Sorbed Water on the Dielectric Properties of Acetylene-Terminated Polyimide Resins and Their Application to a Humidity Sensor
}

\author{
M. Matsuguchi, Y. Sadaoka, K. Nosaka, M. Ishibashi, and Y. Sakai \\ Department of Applied Chemistry, Faculty of Engineering, Ehime University, Matsuyama, Ehime 790, Japan
}

T. Kuroiwa and A. Ito

Yamatake-Honeywell Company, Limited, Fujisawa Factory, Fujisawa, Kanagawa 251, Japan

\section{ABSTRACT}

A cured acetylene-terminated polyisoimide oligomer was used to prepare a capacitive-type humidity sensor. Sorption behavior of water on the cured film was examined by measuring the dielectric constant and water content. The amount of sorbed water was small and the sorbed water did not form clusters. This is due to the hydrophobic nature and rigid structure of the film. The sorption behavior reflects its excellent sensor properties, i.e., low hysteresis, low temperature coefficient, durability against acetone vapor, and long-term stability in a high temperature and humid atmosphere. Among the polyimides prepared by curing the oligomers with different chain lengths, the most suitable composition for a reliable capacitive-type humidity sensor was API-3-API-1.

Recent research concerning capacitive-type humidity. sensors using polymers tends toward microfabrication because these sensors possess properties such as linear sensing output for humidity changes and ease of thin-film preparation. As sensor materials, cellulose derivatives and polyimides have been examined. However, the materials used so far were unsatisfactory in practical applications with respect to hysteresis, stability, reversibility, etc. To solve these disadvantages, the sensing mechanism must be clarified, i.e., the sorption behavior of water molecules on the thin film and the correlation between water sorption ability and dielectric behavior. Some requirements for fabricating the capacitive-type humidity sensors have been clarified, ${ }^{1,2}$ i.e., low hygroscopicity and rigid structure.

Since polyimides possess high workability, excellent thermal and chemical stability, low hygroscopicity, low solubility to common organic solvents, etc., they are used for adhesives, coatings, and film applications for electronic devices. It is well known that polyimide, e.g., Kapton, also has been used for capacitive-type humidity sensors. ${ }^{3-7}$ The sensing characteristics of a humidity sensor using polyimide thin films are excellent except for stability in a humid atmosphere at higher temperatures. Most polyimide thin films used so far have been prepared by polycondensation of the polyamic acid precursor. Disadvantages of these films are as follows; $(i)$ unreacted sites are likely to be present, and (ii) microvoids may arise from volatile byproducts such as water. Recently new polyimide resins (acetylene-terminated polyisoimide oligomers) have been reported. ${ }^{8,9}$ The new resins are preferable materials for fabricating capacitive-type humidity sensors since the starting materials are polyimide oligomers which are soluble in some organic solvents and polymerization proceeds without by-products. Further, each polyimide oligomer is cross-linked and leads to the formation of a rigid and hydrophobic film without microvoids, and the chemical and 